\title{
The stability of cannon position on tank prototype using PID controller
}

\author{
Dimas Farid Arief Putra, Ahmad Syahril Muharom \\ Department of Electrical Engineering, Universitas Multimedia Nusantara, Indonesia
}

\begin{tabular}{|c|c|}
\hline Article Info & ABSTRACT \\
\hline Article history: & Tank is a war vehicle made of steel that can be operated on various fields. \\
\hline Received Aug 30, 2020 & With various fields and a large amount of terrain that the tank had to pass, \\
\hline Revised Jul 28, 2021 & the cannon be able to fire right on the target. This study discusses the \\
\hline Accepted Aug 4, 2021 & $\begin{array}{l}\text { stability of the position of the cannon on the tank prototype using the PID } \\
\text { control system. PID values are obtained by using the Ziegler-Nichols tuning }\end{array}$ \\
\hline Keywords: & $\begin{array}{l}\text { formula and simulink. The system using Arduino MEGA } 2560 \text { as } \\
\text { microcontroller, gyroscope \& accelerometer for the feedback sensor and }\end{array}$ \\
\hline Cannon & cannon that driven using three servos that representing the $x$-axis, $y$-axis and \\
\hline PID & $\begin{array}{l}\mathrm{Z} \text {-axis. The highest average error value is } 4.67 \text { degrees with an overall } \\
\text { average value of } 2.29 \text { degrees and an accuracy percentage of } 98 \% \text { when the }\end{array}$ \\
\hline Simulink & tank tilted randomly on the $\mathrm{x}$-axis, $\mathrm{y}$-axis and z-axis. \\
\hline Stability & \\
\hline
\end{tabular}

This is an open access article under the $\underline{C C B Y-S A}$ license.

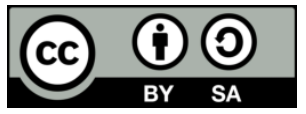

\section{Corresponding Author:}

Ahmad Syahril Muharom

Department of Electrical Engineering

Universitas Multimedia Nusantara

Jl. Scientia Boulevard, Gading, Kec. Serpong, Tangerang, Banten 15227

Email: ahmad.syahril@umn.ac.id

\section{INTRODUCTION}

The application of robotic technology is very helpful in terms of national defense [1] and one of the examples of its use is in tank vehicle. Tanks are war vehicles with robotic technology that can be operated in urban, rural, field and even desert areas [2]. With a large amount of terrain that the tank had to pass, this made it necessary for the tank to be able to stabilize the cannon so that the cannon be able to fire right on the target [3]. Various control systems can be applied to create stability in the tank cannon and one of them is the proportional integral and derivative (PID) control which is a classic control system. This classic control system can be used because of its stability and a good controller to reduce system oscillations [4]-[7].

The gyroscope sensor is a device used to measure the rotational speed or the rate of change in angles over time [8]-[11]. The accelerometer sensor is a device used to measure the value of acceleration, gravitational acceleration and also acceleration of motion [12]-[14]. The combination of the two sensor data can be used as a data source for the inertial measurement unit (IMU) [15]. This study used IMU 6 axes that consisting of 3 axes gyroscope sensor and 3 axes accelerometer sensor [16], [17].

PID controllers are very popular in the industrial section because of its reliability, applicability and simplicity [6], [18]. PID can be tuned using the Ziegler-Nichols (ZN) tuning method [19] which is the most popular method because of its ease of use among all of the PID tuning method [20]-[23]. PID can be used to stabilize DC motor [24]-[26] and servos [27]-[29].

In the previous search, researchers in conducting their research on tank servo systems are using one or two axes coordinate [29], [30], discuss about controlling cannon on the elevation axis using PID [31], 
using PID controller where the servo of cannon is able to pan left or right [1], [32], discuss about controlling tank using two axes coupling. To improve stability on the cannon, this study will discuss stabilizing cannon on yaw, pitch and roll coordinates when the tank moves from one place to another.

\section{RESEARCH METHOD}

\subsection{System block diagram}

This system was designed to create a stable position of the cannon on the tank prototype. This system consists of a controller in the form of Arduino MEGA 2560. Then an accelerator in the form of a cannon and also a gyroscope $\&$ accelerometer sensor for the feedback that is used for the PID control system. This system works by means of the user first determining the angular position of the $x, y$ and $z$ axes as a reference point of the cannon position. After that, the angular position will be converted to a pulse width modulation (PWM) value to move the servos as its actuator. Gyroscope \& accelerometer sensor serves to check whether there are changes in the angle or position of the tank. The values from the gyroscope \& accelerometer sensor in the form of degrees per second will later be converted into an angular position, and after that it will be compared with the reference of the angular position to see the difference value. If a different value is obtained between the gyroscope \& accelerometer sensor readings and the reference of the angular position, the controller will do the calculation and correcting the value of the PWM to move the servos to a reference angle. This system block diagram can be seen in Figure 1.

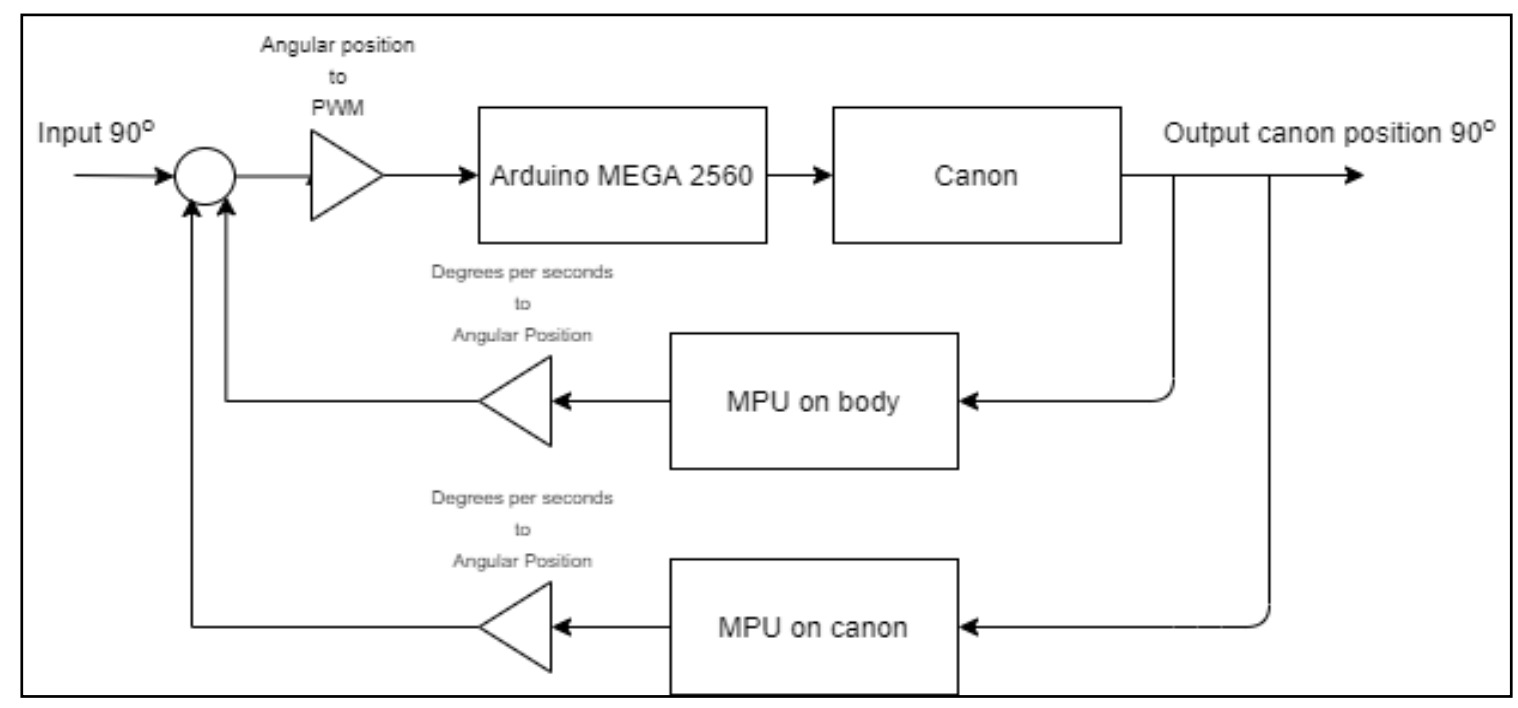

Figure 1. System block diagrams

\subsection{System flowchart}

The system will perform the initialization process first. In the initialization process, there is a setpoint value from each axis position ( $x$-axis, $y$-axis and $z$-axis) which will become the reference value. Then, the gyroscope which works as a position sensor will check whether the position of the $x$-axis is having the same value as the reference value or not. If the difference in value is obtained, the controller will perform the calculation of the $\mathrm{kp}$, ki and $\mathrm{kd}$ for later use of these as the PID value on the servo. After that, the system will check the position of the $y$-axis and the $z$-axis. If there is a difference with the reference value, the controller will perform the same process as mentioned above. This process will be carried out repeatedly so that the position of the cannon through the $x$-axis, $y$-axis and $z$-axis will always be stable at a predetermined reference value. An explanation of the flowchart can be seen in Figure 2.

\subsection{Hardware design}

This study using Arduino MEGA 2560 as a microcontroller that controls the entire cannon position stability system on the prototype tank. Then the actuators are using servo motor MG996R servos for each $x, y$ and $\mathrm{z}$ axes. For the feedback sensors, it uses two MPU6050 (gyroscope \& accelerometer) sensors that are placed on the body of the tank and on the tip of the cannon. Those sensors are connected to the I2C pin on the Arduino MEGA 2560 as shown in Figures 3-5. 


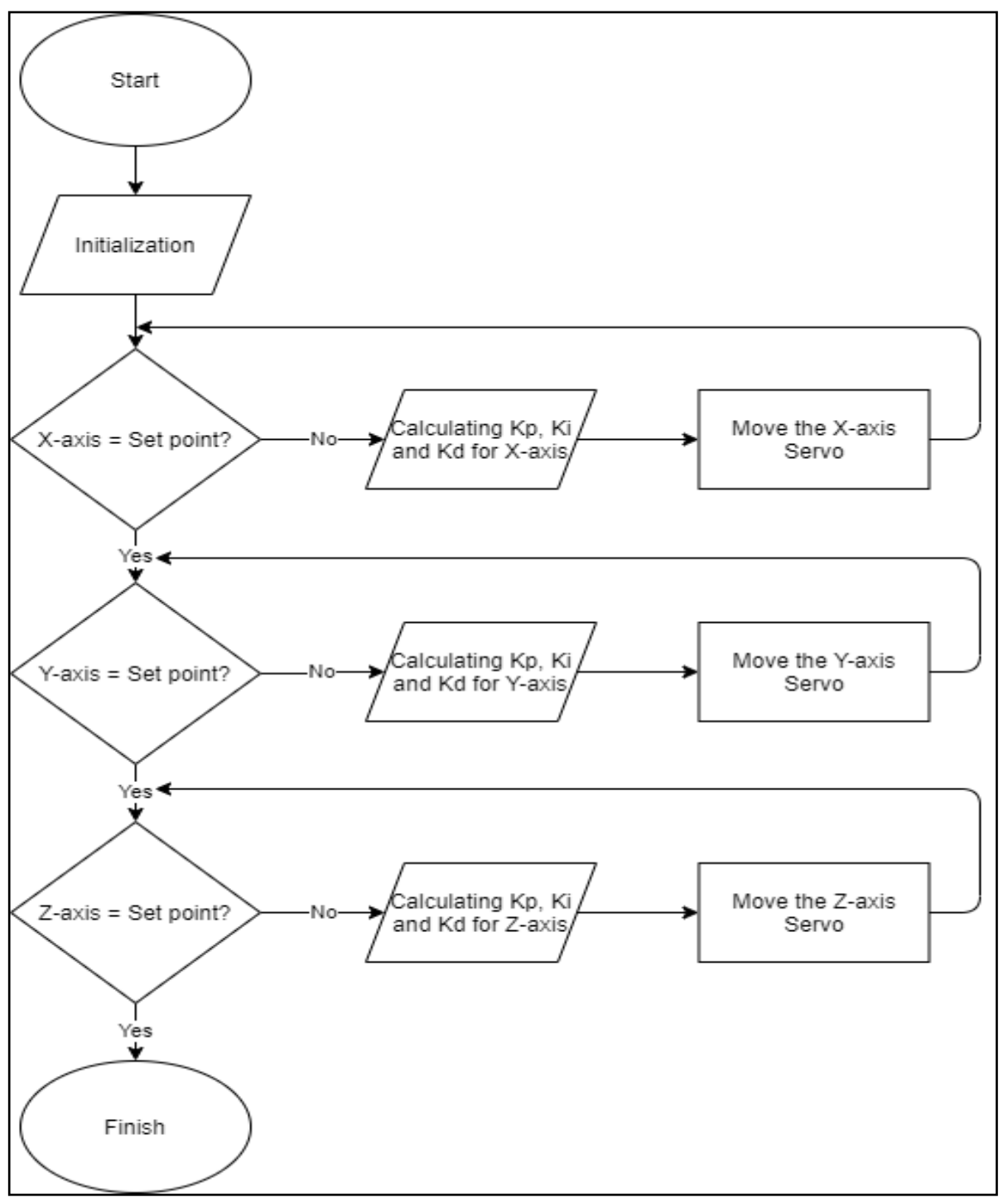

Figure 2. System flowchart

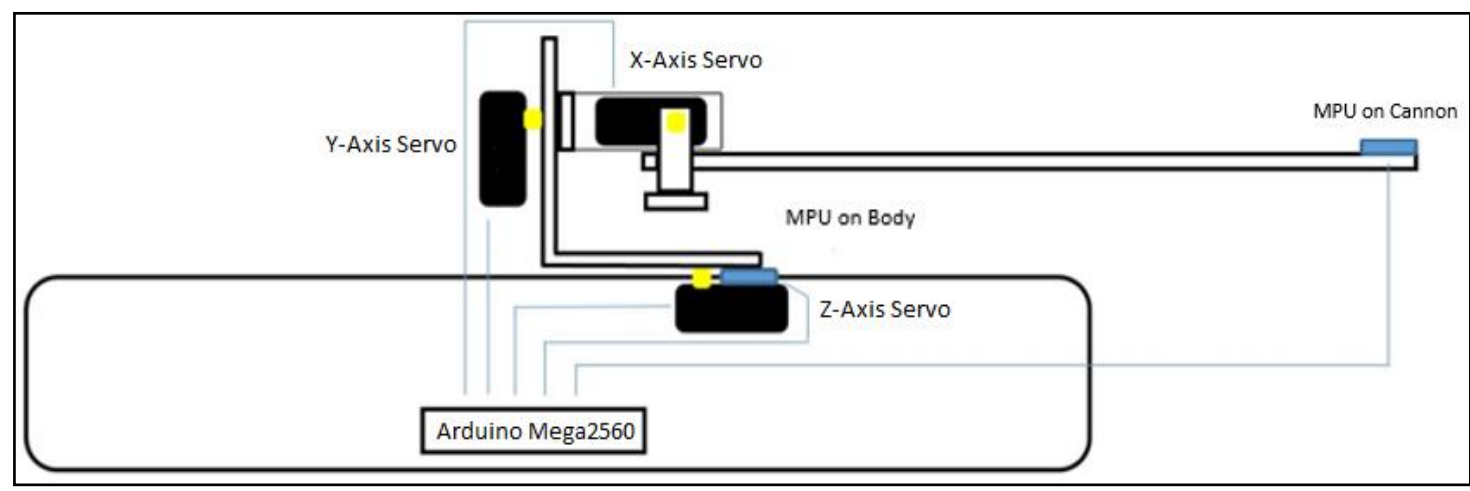

Figure 3. Control mechanism on the tank prototype (side view) 


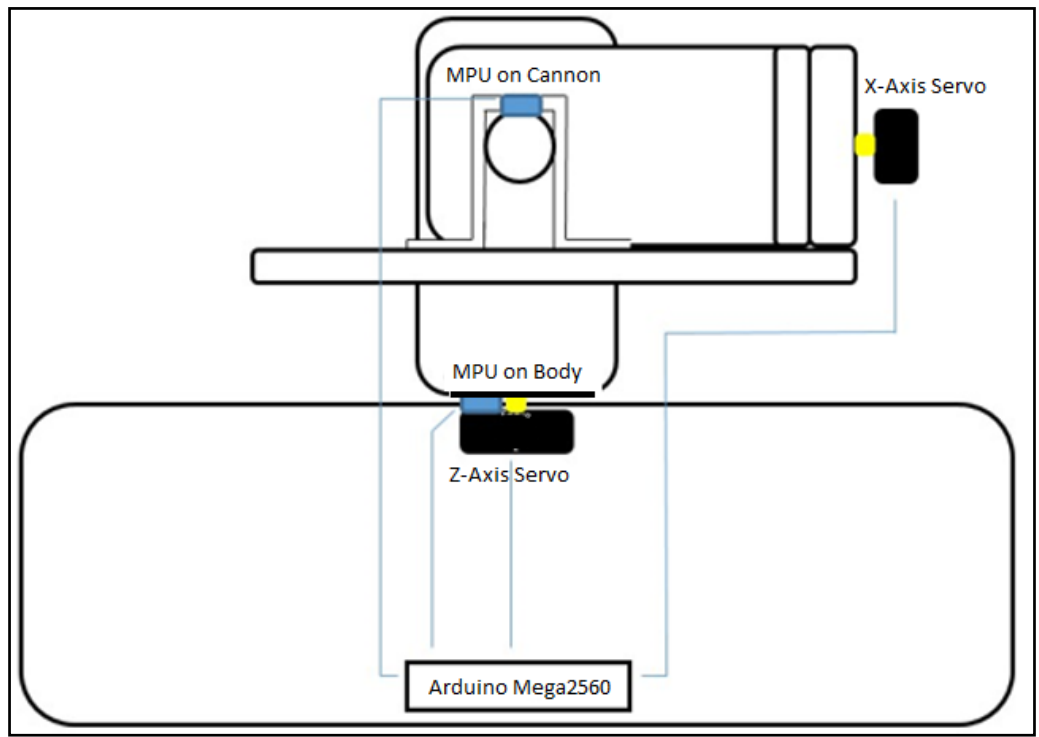

Figure 4. Control mechanism on the tank prototype (front view)

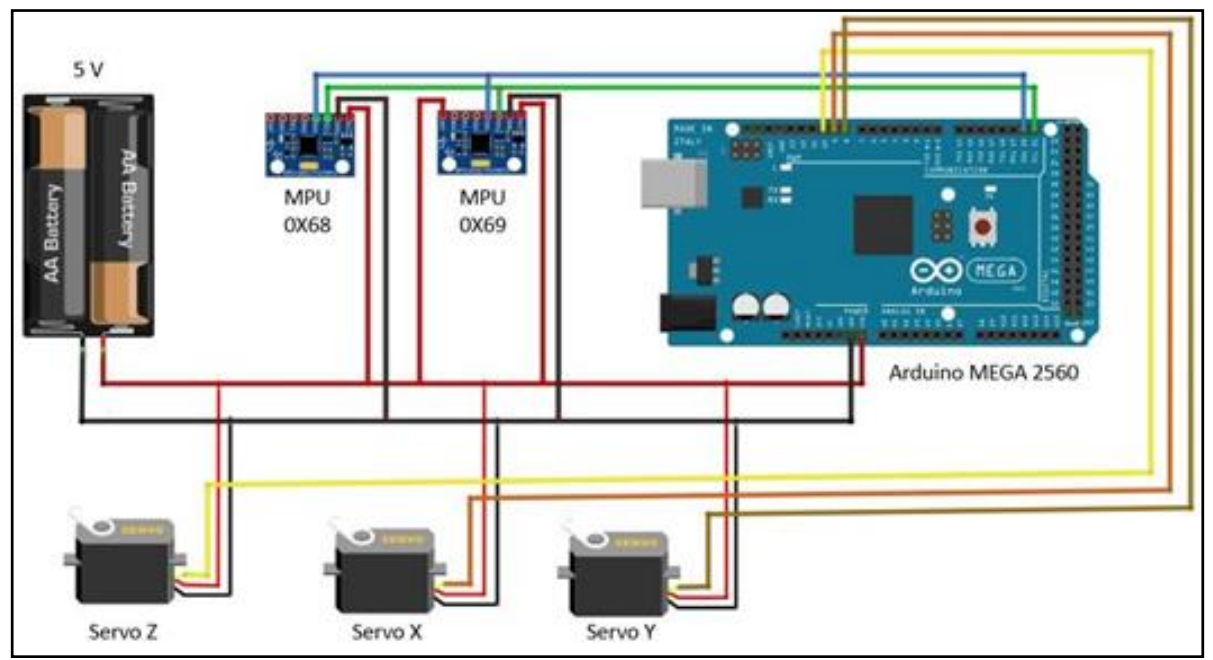

Figure 5. Circuit diagram of tank prototype

\subsection{Transfer function of $D C$ servo motor}

The transfer function of the DC servo motor that is applied in block Simulink and illustrated in figure 6 are obtained by modifying the equation from Widhiada [33].

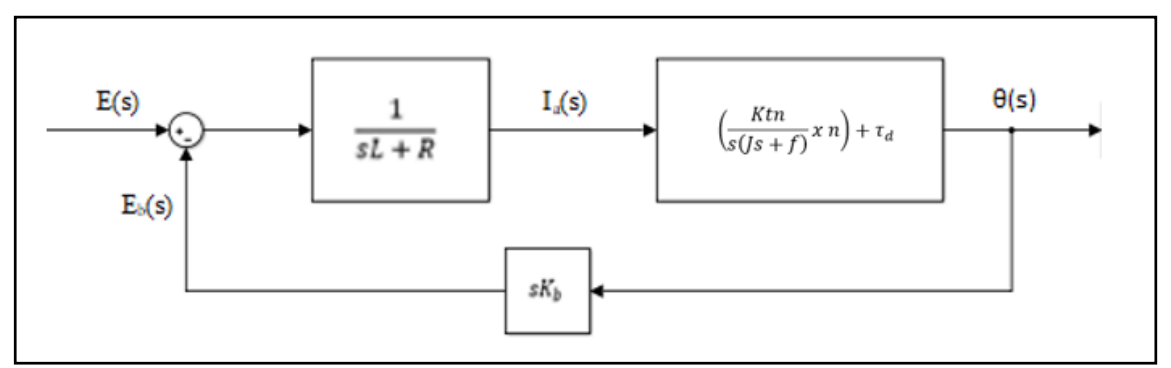

Figure 6. The transfer function of DC servo motor 
where,

$\mathrm{R}=$ armature resistor $(\Omega)$

$\mathrm{L} \quad=$ armature inductance $(\mathrm{H})$

$\mathrm{i}_{\mathrm{a}} \quad=$ armature current $(\mathrm{A})$

$\mathrm{J}=$ moment inertia motor $\left(\mathrm{Kgm}^{2}\right)$

$\mathrm{f}_{\mathrm{o}}=$ coefficient viscous motor and load $\left(\frac{\mathrm{Wm}}{\mathrm{rad} / \mathrm{gec}}\right)$

$\mathrm{K}_{\mathrm{tn}} \quad=$ motor torque constant

$\tau_{\mathrm{d}} \quad=$ disturbance torque

Then by entering the values for those parameters that are shown in Figure 6, the transfer function value of each servo is shown in (1) to (3).

$$
\begin{aligned}
& \text { TFx-axis servo }=\frac{0.000003234 a^{2}+0.00008085 s+0.117}{0.000002545 s^{3}+0.00011636 s^{2}+0.00484 s} \\
& \text { TFy-axis servo }=\frac{0.0000008154 s^{2}+0.000002038 s+0.117}{0.000002486 s^{3}+0.0001624 s^{2}+0.00484 s} \\
& \text { TFz-axis servo }=\frac{0.000005272 s^{2}+0.0001318 s+0.117}{0.000002585 s^{3}+0.0001646 s^{2}+0.00484 s}
\end{aligned}
$$

Then by using the ZN tuning formula [19] and Simulink, the Kp, Ki and Kd (PID constant) values are obtained as shown in the Tables 1 to 3 and Figures 7 to 9 .

Table 1. ZN type 2 for servo $\mathrm{x}$

\begin{tabular}{cccc}
\hline Type & $\mathrm{Kp}$ & $\mathrm{Ki}$ & $\mathrm{Kd}$ \\
\hline Classical PID & 1.772280 & 25.872701 & 0.030350 \\
P & 1.476900 & 0.000000 & 0.000000 \\
PI & 1.329210 & 11.642715 & 0.000000 \\
PD & 2.363040 & 0.000000 & 0.040467 \\
Some Overshoot & 0.984600 & 14.373723 & 0.044963 \\
No Overshoot & 0.590760 & 8.624234 & 0.026978 \\
\hline
\end{tabular}

Table 2. ZN type 2 for servo y

\begin{tabular}{cccc}
\hline Type & $\mathrm{Kp}$ & $\mathrm{Ki}$ & $\mathrm{Kd}$ \\
\hline Classical PID & 1.663398 & 24.283182 & 0.028486 \\
$\mathrm{P}$ & 1.386165 & 0.000000 & 0.000000 \\
$\mathrm{PI}$ & 1.247549 & 10.927432 & 0.000000 \\
PD & 2.217864 & 0.000000 & 0.037981 \\
Some Overshoot & 0.924110 & 13.490657 & 0.042201 \\
No Overshoot & 0.554466 & 8.094394 & 0.025321 \\
\hline
\end{tabular}

Table 3. ZN type 2 for servo $\mathrm{z}$

\begin{tabular}{cccc}
\hline Type & $\mathrm{Kp}$ & $\mathrm{Ki}$ & $\mathrm{Kd}$ \\
\hline Classical PID & 1.889279 & 27.989324 & 0.031882 \\
P & 1.574400 & 0.000000 & 0.000000 \\
PI & 1.416960 & 12.595196 & 0.000000 \\
PD & 2.519039 & 0.000000 & 0.042509 \\
Some Overshoot & 1.049600 & 15.549625 & 0.047232 \\
No Overshoot & 0.629760 & 9.329775 & 0.028339 \\
\hline
\end{tabular}

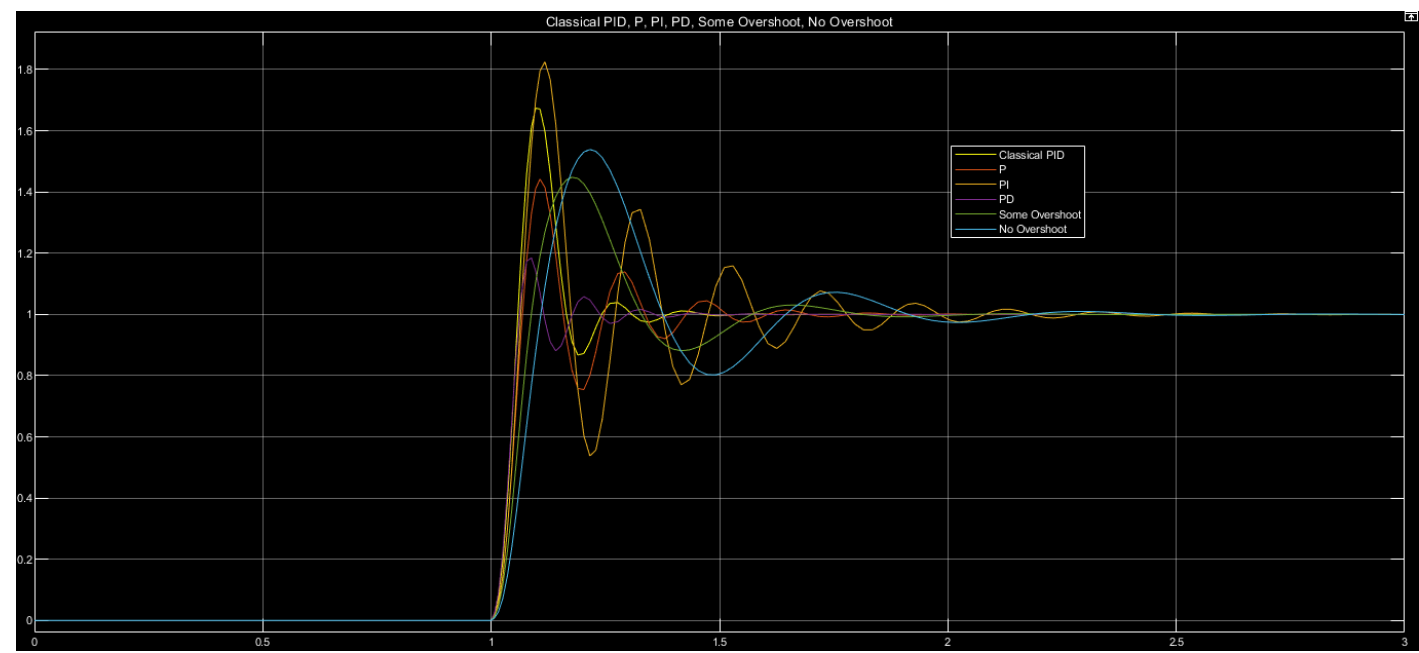

Figure 7. Response of $\mathrm{ZN}$ type 2 for servo $\mathrm{x}$ 


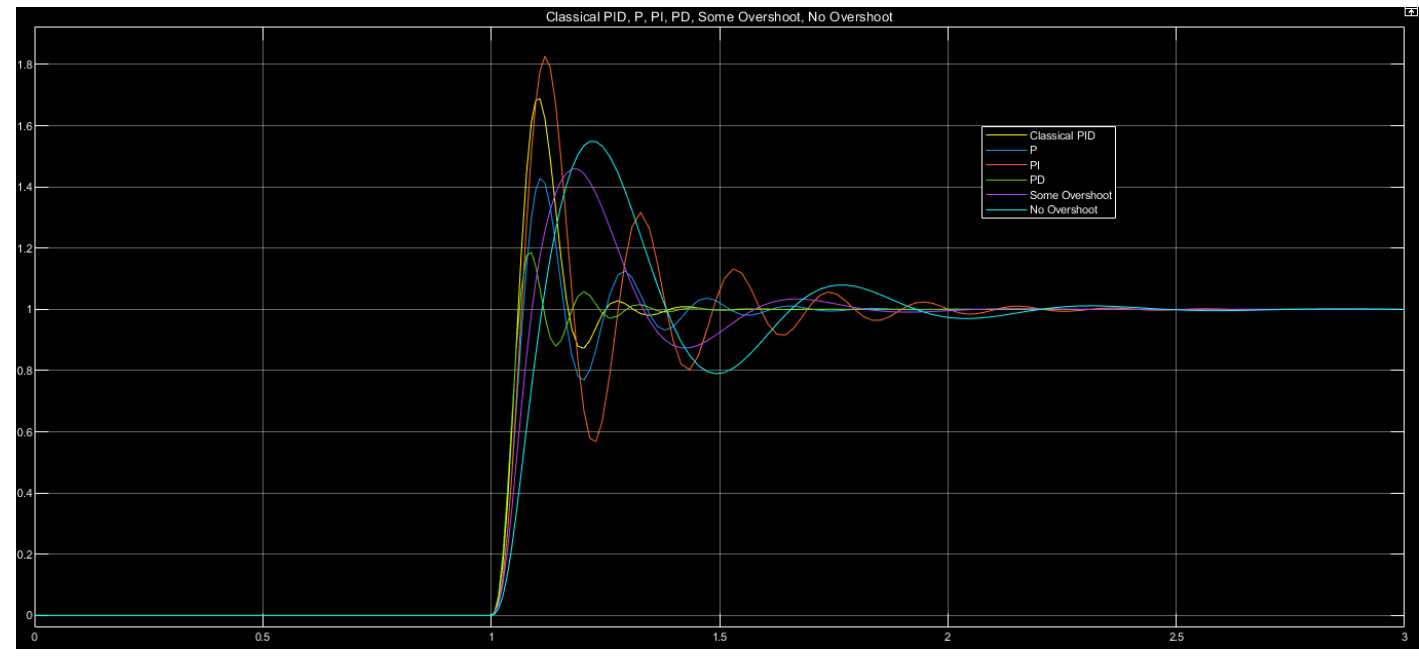

Figure 8. Response of ZN type 2 for servo y

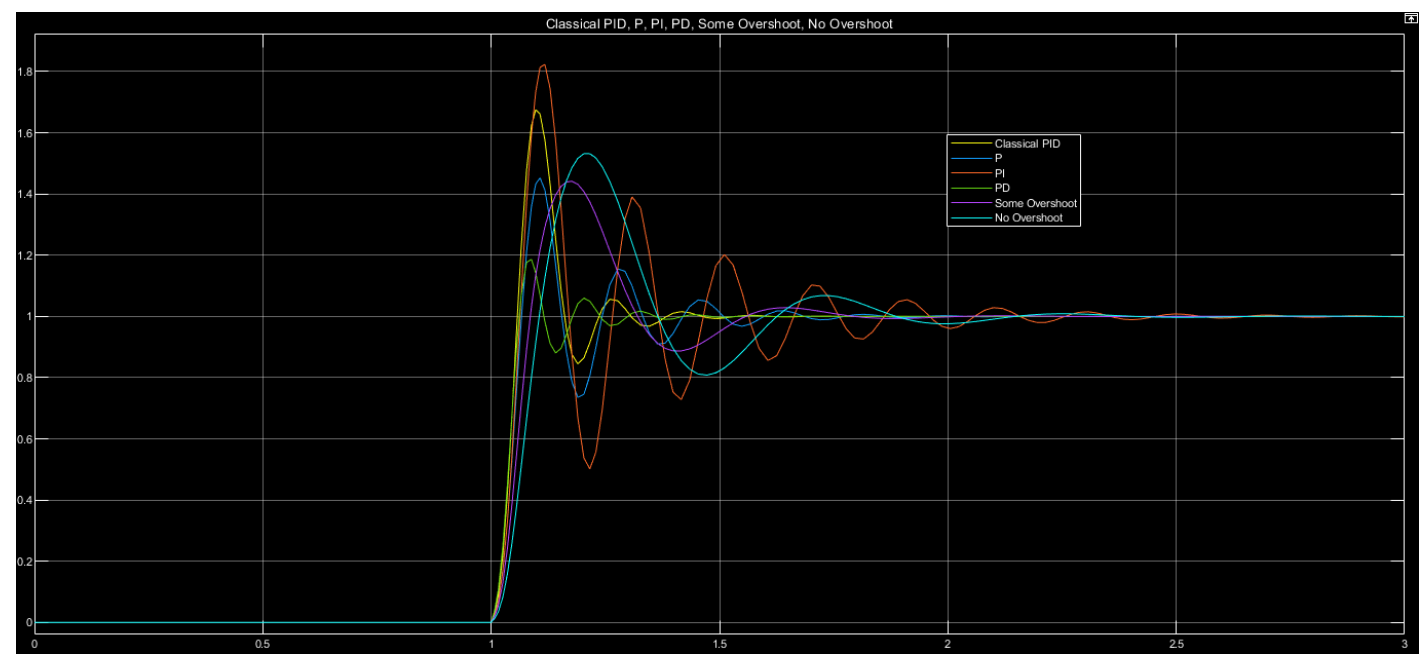

Figure 9. Response of $\mathrm{ZN}$ type 2 for servo $\mathrm{z}$

\section{RESULTS AND ANALYSIS}

The testing of this system is carried out with 4 different tests. Testing on the $x$-axis only, $y$-axis only, $z$-axis only, and the whole servo. When test on the $x$-axis only, first the value of servo $\mathrm{x}$ is adjusted according to the PID value. Then the value of servo $y$ and servo $\mathrm{z}$ is set with a reference value of 90 degrees (respect to gravity). After the whole servo value is set, the position of the body of the tank is tilted every 5 degrees and the output position value of the tip of the cannon is recorded to see the stability of the system. Then, the output value of each axis is seen whether it remains at the reference position or there is a change. The same steps and procedure are carried out in the testing on the $y$ - \& $z$-axis only.

For testing on the whole servo, each of the servos is adjusted with each PID value. After the whole servo value is set, the position of the body of the tank is tilted randomly 30 times and the output position value of the tip of the cannon is recorded and compared with the reference value to see the stability of the system. The result of the whole test can be seen in Tables 4 to 6 .

\subsection{Testing on the $X$-axis}

Based on the test on the $x$-axis only which can be seen in Table 4 above, the following results were obtained:

- $\quad$ The largest error value on the $x$-axis, with an error value of 3 degrees is obtained when the tank body is tilted at a position of 100 degrees. Then the average error on this axis is 1.3 degrees. 
- The largest error value is on the $y$-axis, with an error value of 1 degree obtained when the tank body is tilted at a position of 75 and 110 degrees. Then the average error on this axis is 0.2 degrees.

- The largest error value is on the $z$-axis, with an error value of 3 degrees obtained when the tank body is tilted at a position of 115 degrees. Then the average error on this axis is 0.9 degrees.

- The largest error value is obtained when the tank body is tilted by 100, 115 and 120 degrees. The average error value is 1.33 degrees in the three positions.

- $\quad$ Overall, this test has a maximum error value of 3 degrees and an average error value of 0.8 degrees.

Table 4. X-axis results

\begin{tabular}{|c|c|c|c|c|c|c|c|c|}
\hline \multirow{3}{*}{ Body-X } & \multicolumn{6}{|c|}{$\mathrm{X}$} & \multirow{3}{*}{ Max. } & \multirow{3}{*}{ Avg. } \\
\hline & \multicolumn{2}{|c|}{$\mathrm{X}$} & \multicolumn{2}{|c|}{$\mathrm{Y}$} & \multicolumn{2}{|c|}{$\mathrm{Z}$} & & \\
\hline & Cannon & Error & Cannon & Error & Cannon & Error & & \\
\hline 75 & 90 & 0 & 91 & 1 & 90 & 0 & 1 & 0.33 \\
\hline 80 & 91 & 1 & 90 & 0 & 90 & 0 & 1 & 0.33 \\
\hline 85 & 92 & 2 & 90 & 0 & 90 & 0 & 2 & 0.67 \\
\hline 90 & 90 & 0 & 90 & 0 & 90 & 0 & 0 & 0 \\
\hline 95 & 92 & 2 & 90 & 0 & 90 & 0 & 2 & 0.67 \\
\hline 100 & 93 & 3 & 90 & 0 & 89 & 1 & 3 & 1.33 \\
\hline 105 & 92 & 2 & 90 & 0 & 89 & 1 & 2 & 1 \\
\hline 110 & 90 & 0 & 91 & 1 & 88 & 2 & 2 & 1 \\
\hline 115 & 91 & 1 & 90 & 0 & 87 & 3 & 3 & 1.33 \\
\hline 120 & 92 & 2 & 90 & 0 & 88 & 2 & 2 & 1.33 \\
\hline Max. & 93 & 3 & 91 & 1 & 90 & 3 & & \\
\hline Avg. & 91.3 & 1.3 & 90.2 & 0.2 & 89.1 & 0.9 & & \\
\hline
\end{tabular}

\subsection{Testing on the $Y$-axis} obtained:

Based on the test on the $y$-axis only which can be seen in Table 5 above, the following results were

- The largest error value is on the $\mathrm{x}$-axis, with an error value of 1 degree obtained when the tank body is tilted at a position of 85 and 115 degrees. Then the average error on this axis is 0.17 degrees.

- $\quad$ The largest error value is on the y-axis, with an error value of 3 degrees obtained when the tank body is tilted at a position of 65 degrees. Then the average error on this axis is 0.58 degrees.

- The largest error value is on the z-axis, with an error value of 3 degrees obtained when the tank body is tilted at a position of 60 and 65 degrees. Then the average error on this axis is 0.92 degrees.

- $\quad$ The largest error value is obtained when the tank body is tilted by 65 degrees. The average error value is 2 degrees at that position.

- $\quad$ Overall, this test has a maximum error value of 3 degrees and an average error value of 0.56 degrees.

Table 5. Y-axis results

\begin{tabular}{|c|c|c|c|c|c|c|c|c|}
\hline \multirow{3}{*}{ Body-Y } & \multicolumn{6}{|c|}{$\mathrm{Y}$} & \multirow{3}{*}{ Max. } & \multirow{3}{*}{ Avg. } \\
\hline & \multicolumn{2}{|c|}{$X$} & \multicolumn{2}{|c|}{$Y$} & \multicolumn{2}{|c|}{$\mathrm{Z}$} & & \\
\hline & Cannon & Error & Cannon & Error & Cannon & Error & & \\
\hline 60 & 90 & 0 & 91 & 1 & 87 & 3 & 3 & 1.33 \\
\hline 65 & 90 & 0 & 93 & 3 & 87 & 3 & 3 & 2 \\
\hline 70 & 90 & 0 & 91 & 1 & 88 & 2 & 2 & 1 \\
\hline 75 & 90 & 0 & 90 & 0 & 88 & 2 & 2 & 0.67 \\
\hline 80 & 90 & 0 & 91 & 1 & 89 & 1 & 1 & 0.67 \\
\hline 85 & 91 & 1 & 90 & 0 & 90 & 0 & 1 & 0.33 \\
\hline 90 & 90 & 0 & 90 & 0 & 90 & 0 & 0 & 0 \\
\hline 95 & 90 & 0 & 90 & 0 & 90 & 0 & 0 & 0 \\
\hline 100 & 90 & 0 & 90 & 0 & 90 & 0 & 0 & 0 \\
\hline 105 & 90 & 0 & 90 & 0 & 90 & 0 & 0 & 0 \\
\hline 110 & 90 & 0 & 90 & 0 & 90 & 0 & 0 & 0 \\
\hline 115 & 89 & 1 & 89 & 1 & 90 & 0 & 1 & 0.67 \\
\hline Max. & 91 & 1 & 93 & 3 & 90 & 3 & & \\
\hline Avg. & 90 & 0.17 & 90.42 & 0.58 & 89.08 & 0.92 & & \\
\hline
\end{tabular}

\subsection{Testing on the $Z$-axis}

Based on the test on the $z$-axis only which can be seen in Table 6 above, the following results were obtained: 
- The largest error value on the $\mathrm{x}$-axis, with an error value of 3 degrees is obtained when the tank body is tilted at positions 5, 10, 15, 20, 25, 30 and 35 degrees. Then the average error on this axis is 0.77 degrees.

- $\quad$ The largest error value is on the y-axis, with an error value of 3 degrees obtained when the tank body is tilted at a position of 30 and 150 degrees. Then the average error on this axis is 0.83 degrees.

- The largest error value is on the z-axis, with an error value of 2 degrees obtained when the tank body is tilted at positions 5, 15, 45, 60, 155, 170 and 175 degrees. Then the average error on this axis is 0.89 degrees.

- $\quad$ The largest error value is obtained when the tank body is tilted by 30 degrees. The average error value is 2.33 degrees in that position.

- Overall, this test has a maximum error value of 3 degrees and has an average error value of 0.83 degrees.

Table 6. Z-axis results

\begin{tabular}{|c|c|c|c|c|c|c|c|c|}
\hline \multirow{3}{*}{ Body-Z } & \multicolumn{6}{|c|}{$\mathrm{Z}$} & \multirow{3}{*}{ Max. } & \multirow{3}{*}{ Avg. } \\
\hline & \multicolumn{2}{|l|}{$\mathrm{X}$} & \multicolumn{2}{|c|}{$\mathrm{Y}$} & \multicolumn{2}{|l|}{$\mathrm{Z}$} & & \\
\hline & Cannon & Error & Cannon & Error & Cannon & Error & & \\
\hline 5 & 87 & 3 & 90 & 0 & 88 & 2 & 3 & 1.67 \\
\hline 10 & 87 & 3 & 89 & 1 & 89 & 1 & 3 & 1.67 \\
\hline 15 & 87 & 3 & 89 & 1 & 88 & 2 & 3 & 2 \\
\hline 20 & 87 & 3 & 89 & 1 & 88 & 2 & 3 & 2 \\
\hline 25 & 87 & 3 & 88 & 2 & 89 & 1 & 3 & 2 \\
\hline 30 & 87 & 3 & 87 & 3 & 89 & 1 & 3 & 2.33 \\
\hline 35 & 87 & 3 & 89 & 1 & 90 & 0 & 3 & 1.33 \\
\hline 40 & 88 & 2 & 89 & 1 & 89 & 1 & 2 & 1.33 \\
\hline 45 & 88 & 2 & 90 & 0 & 88 & 2 & 2 & 1.33 \\
\hline 50 & 89 & 1 & 90 & 0 & 88 & 2 & 2 & 1 \\
\hline 55 & 89 & 1 & 89 & 1 & 89 & 1 & 1 & 1 \\
\hline 60 & 90 & 0 & 90 & 0 & 88 & 2 & 2 & 0.67 \\
\hline 65 & 90 & 0 & 90 & 0 & 89 & 1 & 1 & 0.33 \\
\hline 70 & 90 & 0 & 90 & 0 & 89 & 1 & 1 & 0.33 \\
\hline 75 & 90 & 0 & 90 & 0 & 89 & 1 & 1 & 0.33 \\
\hline 80 & 90 & 0 & 90 & 0 & 90 & 0 & 0 & 0 \\
\hline 85 & 90 & 0 & 91 & 1 & 90 & 0 & 1 & 0.33 \\
\hline 90 & 90 & 0 & 90 & 0 & 90 & 0 & 0 & 0 \\
\hline 95 & 90 & 0 & 90 & 0 & 90 & 0 & 0 & 0 \\
\hline 100 & 90 & 0 & 90 & 0 & 90 & 0 & 0 & 0 \\
\hline 105 & 90 & 0 & 90 & 0 & 90 & 0 & 0 & 0 \\
\hline 110 & 90 & 0 & 90 & 0 & 90 & 0 & 0 & 0 \\
\hline 115 & 90 & 0 & 90 & 0 & 90 & 0 & 0 & 0 \\
\hline 120 & 90 & 0 & 90 & 0 & 90 & 0 & 0 & 0 \\
\hline 125 & 90 & 0 & 91 & 1 & 90 & 0 & 1 & 0.33 \\
\hline 130 & 90 & 0 & 92 & 2 & 90 & 0 & 2 & 0.67 \\
\hline 135 & 90 & 0 & 92 & 2 & 90 & 0 & 2 & 0.67 \\
\hline 140 & 90 & 0 & 92 & 2 & 89 & 1 & 2 & 1 \\
\hline 145 & 90 & 0 & 92 & 2 & 89 & 1 & 2 & 1 \\
\hline 150 & 90 & 0 & 93 & 3 & 89 & 1 & 3 & 1.33 \\
\hline 155 & 90 & 0 & 92 & 2 & 88 & 2 & 2 & 1.33 \\
\hline 160 & 90 & 0 & 92 & 2 & 89 & 1 & 2 & 1 \\
\hline 165 & 90 & 0 & 91 & 1 & 89 & 1 & 1 & 0.67 \\
\hline 170 & 90 & 0 & 90 & 0 & 88 & 2 & 2 & 0.67 \\
\hline 175 & 90 & 0 & 90 & 0 & 88 & 2 & 2 & 0.67 \\
\hline Max. & 90 & 3 & 93 & 3 & 90 & 2 & & \\
\hline Avg. & 89.23 & 0.77 & 90.2 & 0.83 & 89.11 & 0.89 & & \\
\hline
\end{tabular}

\subsection{Testing on the $X, Y$ and $Z$ axes}

Based on the test in Table 7 above, the following results were obtained:

- $\quad$ The largest error value on the $\mathrm{x}$-axis, with an error value of 6 degrees was obtained when the tank body was tilted in the 12th, 16th and 27-30th experiments. Then the average error on this axis is 2.77 degrees.

- $\quad$ The largest error value on the y-axis, with an error value of 8 degrees was obtained when the tank body was tilted in the 20th experiment. Then the average error on this axis was 2.9 degrees.

- $\quad$ The largest error value on the z-axis, with an error value of 4 degrees was obtained when the tank body was tilted in the 16 th experiment. Then the average error on this axis was 1.2 degrees. 
- $\quad$ The largest error value is obtained when the tank body is tilted by 90 degrees on the $\mathrm{x}$-axis, 102 degrees on the $y$-axis and 112 degrees on the z-axis. The average error value is 4.67 degrees at that position.

- Overall, this test has a maximum error value of 8 degrees and has an average error value of 2.29 degrees.

Table 7. Results of $\mathrm{X}, \mathrm{Y}$ and $\mathrm{Z}$ axes

\begin{tabular}{|c|c|c|c|c|c|c|c|c|c|c|c|}
\hline \multirow{2}{*}{ No } & \multirow{2}{*}{ Body-X } & \multirow{2}{*}{ Body-Y } & \multirow{2}{*}{$\begin{array}{c}\text { Body- } \\
\text { Z }\end{array}$} & \multicolumn{2}{|c|}{$X$} & \multicolumn{2}{|c|}{$\mathrm{Y}$} & \multicolumn{2}{|c|}{$\mathrm{Z}$} & \multirow{2}{*}{ Max. } & \multirow{2}{*}{ Avg. } \\
\hline & & & & Cannon & Error & Cannon & Error & Cannon & Error & & \\
\hline 1 & 86 & 93 & 86 & 92 & 2 & 90 & 0 & 90 & 0 & 2 & 0.67 \\
\hline 2 & 86 & 95 & 81 & 90 & 0 & 92 & 2 & 90 & 0 & 2 & 0.67 \\
\hline 3 & 85 & 96 & 75 & 89 & 1 & 92 & 2 & 90 & 0 & 2 & 1 \\
\hline 4 & 85 & 100 & 74 & 87 & 3 & 91 & 1 & 90 & 0 & 3 & 1.33 \\
\hline 5 & 87 & 91 & 80 & 90 & 0 & 92 & 2 & 89 & 1 & 2 & 1 \\
\hline 6 & 90 & 90 & 83 & 90 & 0 & 92 & 2 & 89 & 1 & 2 & 1 \\
\hline 7 & 87 & 80 & 85 & 90 & 0 & 92 & 2 & 89 & 1 & 2 & 1 \\
\hline 8 & 85 & 79 & 93 & 90 & 0 & 89 & 1 & 89 & 1 & 1 & 0.67 \\
\hline 9 & 87 & 74 & 100 & 90 & 0 & 90 & 0 & 90 & 0 & 0 & 0 \\
\hline 10 & 83 & 81 & 111 & 90 & 0 & 87 & 3 & 89 & 1 & 3 & 1.33 \\
\hline 11 & 89 & 89 & 111 & 93 & 3 & 83 & 7 & 88 & 2 & 7 & 4 \\
\hline 12 & 90 & 102 & 112 & 96 & 6 & 83 & 7 & 89 & 1 & 7 & 4.67 \\
\hline 13 & 89 & 90 & 98 & 93 & 3 & 87 & 3 & 88 & 2 & 3 & 2.67 \\
\hline 14 & 96 & 81 & 83 & 95 & 5 & 89 & 1 & 87 & 3 & 5 & 3 \\
\hline 15 & 100 & 82 & 77 & 94 & 4 & 91 & 1 & 87 & 3 & 4 & 2.67 \\
\hline 16 & 98 & 72 & 69 & 96 & 6 & 92 & 2 & 86 & 4 & 6 & 4 \\
\hline 17 & 97 & 87 & 61 & 90 & 0 & 91 & 1 & 87 & 3 & 3 & 1.33 \\
\hline 18 & 100 & 80 & 52 & 93 & 3 & 97 & 7 & 87 & 3 & 7 & 4.33 \\
\hline 19 & 95 & 92 & 50 & 85 & 5 & 92 & 2 & 88 & 2 & 5 & 3 \\
\hline 20 & 96 & 80 & 40 & 94 & 4 & 98 & 8 & 87 & 3 & 8 & 5 \\
\hline 21 & 94 & 90 & 57 & 87 & 3 & 92 & 2 & 90 & 0 & 3 & 1.67 \\
\hline 22 & 93 & 75 & 60 & 93 & 3 & 94 & 4 & 89 & 1 & 4 & 2.67 \\
\hline 23 & 86 & 86 & 71 & 89 & 1 & 90 & 0 & 91 & 1 & 1 & 0.67 \\
\hline 24 & 95 & 90 & 97 & 88 & 2 & 85 & 5 & 90 & 0 & 5 & 2.33 \\
\hline 25 & 97 & 106 & 107 & 90 & 0 & 85 & 5 & 91 & 1 & 5 & 2 \\
\hline 26 & 100 & 91 & 110 & 85 & 5 & 87 & 3 & 90 & 0 & 5 & 2.67 \\
\hline 27 & 99 & 93 & 95 & 84 & 6 & 91 & 1 & 91 & 1 & 6 & 2.67 \\
\hline 28 & 106 & 91 & 86 & 84 & 6 & 93 & 3 & 90 & 0 & 6 & 3 \\
\hline 29 & 95 & 79 & 85 & 84 & 6 & 95 & 5 & 91 & 1 & 6 & 4 \\
\hline 30 & 97 & 74 & 96 & 84 & 6 & 85 & 5 & 90 & 0 & 6 & 3.67 \\
\hline \multirow{2}{*}{\multicolumn{4}{|c|}{$\begin{array}{l}\text { Max. } \\
\text { Avg. }\end{array}$}} & 96 & 6 & 98 & 8 & 91 & 4 & & \\
\hline & & & & 89.83 & 2.77 & 90.23 & 2.9 & 89.07 & 1.2 & & \\
\hline
\end{tabular}

\section{CONCLUSION}

The values of $\mathrm{Kp}, \mathrm{Ki}$ and $\mathrm{Kd}$ that obtained from the Ziegler Nichols type 2 method can be implemented in the system and stabilize the tank cannon. The amount of load on each servo also can affect the value of the transfer function which causes differences in the PID value of each servo. The test was conducted with 4 schemes which are tilted on the $x$-axis only, $y$-axis only, $z$-axis only, and when the tank is tilted randomly on those three axes. The result has shown that the average error value is 0.8 degrees with an accuracy percentage of $99 \%$ when the tank is tilted on the $x$-axis only, the average error value of 0.56 degrees with an accuracy percentage of $99 \%$ when the tank is tilted on the $y$-axis only, the average error value of 0.83 degrees with an accuracy percentage of $99 \%$ when the tank is tilted on the $z$-axis only, and the average error value of 2.29 degrees with an accuracy percentage of $98 \%$ when the tank tilted randomly on the $x$-axis, $y$-axis and $z$-axis. As future works, there are several suggestions that can be given to developing the system so that it can be implemented on the real size tank. First, by using a motor that has a large speed and torque with clear specifications so that the transfer function can be calculated precisely. Then use a sensor with better specifications so that it can provide more accurate and faster results. And a controller with high specifications that can control the whole system so that it can be applied in future work.

\section{REFERENCES}

[1] S. Kuswadi, M. N. Tamara, and Dwi Nugroho H.W., "Gun turret automatic weapon control system design and realization," in 2016 International Symposium on Electronics and Smart Devices (ISESD), Nov. 2016, pp. 30-34, doi: 10.1109/ISESD.2016.7886687.

[2] Ö. Gümüşay, "Intelligent stabilization control of turret subsystems under disturbances from unstructured terrain," PhD Thesis. Ph. D. Diss. Middle East Tech. Univ., 2006. 
[3] Y. Xia, L. Dai, M. Fu, C. Li, and C. Wang, "Application of active disturbance rejection control in tank gun control system,” J. Franklin Inst., vol. 351, no. 4, pp. 2299-2314, Apr. 2014, doi: 10.1016/j.jfranklin.2013.02.003.

[4] P. Bob, "What's All This P-I-D Stuff, Anyhow?," Electron. Des., 1995.

[5] M. D. M. Rahman, S. M. H. Rashid, K. M. R. Hassan, and M. M. Hossain, "Comparison of different control theories on a two wheeled self balancing robot," in AIP conference proceedings, vol. 1980, no. 1, 2018, p. 060005, doi: 10.1063/1.5044373.

[6] Ajiboye A. T, Popoola J. O, Oniyide O, Ayinla S. L, "PID controller for microsatellite yaw-axis attitude control system using ITAE method," TELKOMNIKA (Telecommunication Comput. Electron. Control., vol. 18, no. 2, p. 1001, Apr. 2020, doi: 10.12928/telkomnika.v18i2.14303.

[7] D. F. A. Putra, "Kestabilan Posisi Meriam pada Prototipe Tank Menggunakan Kontroler Pid," Universitas Multimedia Nusantara, 2020.

[8] N. H. Ariffin, N. Arsad, and B. Bais, "Low cost MEMS gyroscope and accelerometer implementation without Kalman Filter for angle estimation," in 2016 International Conference on Advances in Electrical, Electronic and Systems Engineering (ICAEES), Nov. 2016, pp. 77-82, doi: 10.1109/ICAEES.2016.7888013.

[9] Z. Feng and J. Fei, "Super-Twisting Sliding Mode Control for Micro Gyroscope Based on RBF Neural Network," IEEE Access, vol. 6, pp. 64993-65001, 2018, doi: 10.1109/ACCESS.2018.2877398.

[10] A. Sheikhaleh, K. Jafari, and K. Abedi, "Design and Analysis of a Novel MOEMS Gyroscope Using an Electrostatic Comb-Drive Actuator and an Optical Sensing System," IEEE Sens. J., vol. 19, no. 1, pp. 144-150, Jan. 2019, doi: 10.1109/JSEN.2018.2875076.

[11] A. Noordin, M. A. M. Basri, and Z. Mohamed, "Sensor Fusion Algorithm by Complementary Filter for Attitude Estimation of Quadrotor with Low-Cost IMU," TELKOMNIKA (Telecommunication Comput. Electron. Control., vol. 16, no. 2, p. 868, Apr. 2018, doi: 10.12928/telkomnika.v16i2.9020.

[12] B. Firman, "Implementasi Sensor Imu Mpu6050 Berbasis Serial I2c pada Self-Balancing Robot," J. Teknol. Technoscientia, vol. 9, pp. 18-24, 2016, doi: 10.1109/CSPA.2011.5 759837.

[13] N. A. Zakaria, N. A. Rashid, and M. A. Asa'ari, "Development of Fall Risk Detector for Elderly," TELKOMNIKA (Telecommunication Comput. Electron. Control), vol. 16, no. 4, p. 1577, Aug. 2018, doi: 10.12928/telkomnika.v16i4.9066.

[14] J. Song, C. He, R. Wang, C. Xue, and W. Zhang, "A Mathematical Model of a Piezo-Resistive Eight-Beam ThreeAxis Accelerometer with Simulation and Experimental Validation,” Sensors, vol. 18, no. 11, p. 3641, Oct. 2018, doi: $10.3390 / \mathrm{s} 18113641$.

[15] O. Steven Eyobu and D. Han, "Feature Representation and Data Augmentation for Human Activity Classification Based on Wearable IMU Sensor Data Using a Deep LSTM Neural Network," Sensors, vol. 18, no. 9, p. 2892, Aug. 2018, doi: 10.3390/s18092892.

[16] W. Djuriatno, E. Maulana, H. Hasan, E. D. Arisandi, and W. Wijono, "Velocity measurement based on inertial measuring unit," TELKOMNIKA (Telecommunication Comput. Electron. Control., vol. 17, no. 4, p. 1898, Aug. 2019, doi: 10.12928/telkomnika.v17i4.11826.

[17] H. Ahmed and M. Tahir, "Accurate Attitude Estimation of a Moving Land Vehicle Using Low-Cost MEMS IMU Sensors," IEEE Trans. Intell. Transp. Syst., vol. 18, no. 7, pp. 1723-1739, Jul. 2017, doi: 10.1109/TITS.2016.2627536.

[18] H. Maghfiroh, C. Hermanu, M. H. Ibrahim, M. Anwar, and A. Ramelan, "Hybrid fuzzy-PID like optimal control to reduce energy consumption," TELKOMNIKA (Telecommunication Comput. Electron. Control., vol. 18, no. 4, p. 2053, Aug. 2020, doi: 10.12928/telkomnika.v18i4.14535.

[19] J. G. Ziegler and N. B. Nichols, "Optimum Settings for Automatic Controllers," Trans. ASME, vol. 115, pp. 220222, 1942, doi: 10.1115/1.2899060.

[20] M. Nafea, A. R. M. Ali, J. Baliah, and M. S. Mohamed Ali, "Metamodel-based Optimization of a PID Controller Parameters for a Coupled-tank System," TELKOMNIKA (Telecommunication Comput. Electron. Control), vol. 16, no. 4, p. 1590, Aug. 2018, doi: 10.12928/telkomnika.v16i4.9069.

[21] A. Abdulameer, M. Sulaiman, M. S. M. Aras, and D. Saleem, "GUI Based Control System Analysis using PID Controller for Education,” Indones. J. Electr. Eng. Comput. Sci. (IJEECS), vol. 3, no. 1, p. 91, Jul. 2016, doi: 10.11591/ijeecs.v3.i1.pp91-101.

[22] A. Abdulameer, M. Sulaiman, M. Aras, and D. Saleem, "Tuning Methods of PID Controller for DC Motor Speed Control," Indones. J. Electr. Eng. Comput. Sci. (IJEECS), vol. 3, no. 2, p. 343, Aug. 2016, doi: 10.11591/ijeecs.v3.i2.pp343-349.

[23] S. K. Suman and V. K. Giri, "Speed control of DC motor using optimization techniques based PID Controller," in 2016 IEEE International Conference on Engineering and Technology (ICETECH), Mar. 2016, pp. 581-587, doi: 10.1109/ICETECH.2016.7569318.

[24] R. V. Jain, M. V. Aware, and A. S. Junghare, "Tuning of Fractional Order PID controller using particle swarm optimization technique for DC motor speed control," in 2016 IEEE 1st International Conference on Power Electronics, Intelligent Control and Energy Systems (ICPEICES), Jul. 2016, pp. 1-4, doi: 10.1109/ICPEICES.2016.7853070.

[25] X. Chen, M. L. Rahman, and Y. Zhang, "Notice of Violation of IEEE Publication Principles: Adaptive Fuzzy PID speed control of DC belt conveyor system," in 2016 17th IEEE/ACIS International Conference on Software Engineering, Artificial Intelligence, Networking and Parallel/Distributed Computing (SNPD), May 2016, pp. 487490, doi: 10.1109/SNPD.2016.7515945.

[26] A. Tepljakov, E. A. Gonzalez, E. Petlenkov, J. Belikov, C. A. Monje, and I. Petráš, "Incorporation of fractionalorder dynamics into an existing PI/PID DC motor control loop," ISA Trans., vol. 60, pp. 262-273, Jan. 2016, doi: 10.1016/j.isatra.2015.11.012. 
[27] T. Samakwong and W. Assawinchaichote, "PID Controller Design for Electro-hydraulic Servo Valve System with Genetic Algorithm,” Procedia Comput. Sci., vol. 86, pp. 91-94, 2016, doi: 10.1016/j.procs.2016.05.023.

[28] G. Qiang, H. Junfeng, and P. Wei, "PMSM Servo Control System Design Based on Fuzzy PID," in 2017 2nd International Conference on Cybernetics, Robotics and Control (CRC), Jul. 2017, pp. 85-88, doi: 10.1109/CRC.2017.28.

[29] R. H. T. Wicaksono and P. W. Rusimamto, "Perancangan Sistem Kontrol Posisi Sumbu Elevasi Gun Pada Turretgun Menggunakan Kontroler Pid Berbasis Arduino Mega," J. Tek. ELEKTRO, vol. 9, no. 1, 2020.

[30] A. C. Ceceloglu and T. Yildirim, "Modeling and Simulation of Turret Stabilization with Intelligent Algorithms," Procedia Comput. Sci., vol. 154, pp. 377-382, 2019, doi: 10.1016/j.procs.2019.06.054.

[31] W. Budhiharto, E. Irwansyah, S. J. Sembodo, and A. A. S. Gunawan, "Design of Object Tracking for Military Robot Using PID Controller and Computer Vision,” ICIC Express Lett., vol. 14, no. 3, pp. 289-294, 2020, doi: 10.24507/icicel.14.03.289.

[32] S. Yuan, W. Deng, Y. Ge, J. Yao, and G. Yang, "Nonlinear Adaptive Robust Precision Pointing Control of Tank Servo Systems," IEEE Access, vol. 9, pp. 23385-23397, 2021, doi: 10.1109/ACCESS.2021.3054178.

[33] W. Widhiada, T. G. T. Nindhia, and N. Budiarsa, "Robust Control for the Motion Five Fingered Robot Gripper," Int. J. Mech. Eng. Robot. Res., vol. 4, no. 3, pp. 226-232, 2015, doi: 10.18178/ijmerr.4.3.226-232.

\section{BIOGRAPHIES OF AUTHORS}
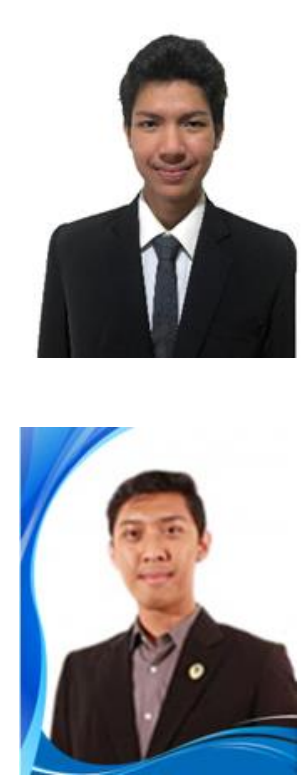

Dimas Farid Arief Putra, known as Dimas is born in Tangerang on $26^{\text {th }}$ April 1998. He is already finished his study as an Electrical Engineering student at Universitas Multimedia Nusantara in July 2020. He has 2 sisters and 3 brothers in his family. He very loved playing basketball with his friends or brothers.

Ahmad Syahril Muharom, known as Syahril, at this time as head of the electrical engineering study program UMN, he was interested in the field of electrical engineering from junior high school until he entered vocational high school in electrical engineering and continued his undergraduate electrical engineering program at the Indonesian University of Education. He earned a Master's degree in Electrical at the Bandung Institute of Technology in 2017 and has a research focus on control engineering and intelligent systems, especially in the field of nonlinear control. He worked as a researcher at the Blackberry Innovation Center (BBIC) ITB in 20142016. Apart from being a researcher, he was also a teaching staff at the Polytechnic STT Textile Bandung in 2015. 